\title{
Comparison of the performance of lipoperoxidation-antioxidant protection system in rats at different periods under immobilization stress effects
}

\author{
Oralbek Z. Ilderbayev ${ }^{1} * \mathbb{D}$, Gulmira M. Zharmakhanova ${ }^{2}$, Assem K. Okassova ${ }^{1}$, Akmaral Zh. Nursafina $^{1}$, \\ Gulzhan O. Ilderbayeva ${ }^{3}$
}

Received: 12 Mar 2020

Published: 6 Sep 2021

\section{Abstract}

Background: Under physiological conditions, the activity of the formation of active oxygen is low. The activity of these processes is intensified under stress-induced situations. This study aimed to investigate the role of free-radical oxidation (FRO) in adrenal tissues and immunocompetent organs and cells in mature white rats after 6 hours of immobilization stress.

Methods: The studies were performed on 40 White male rats of the Wistar line with a bodyweight of 200 to 240 g. Two series of experiments were conducted: I series: determination of indices in intact rats (10 rats); II series: determination of indices after a 6-hour immobilization stress action on them. Animals of II series were divided into 3 groups of 10 rats in each: group 1: those undergoing acute immobilization stress, withdrawal from the experiment in 1 hour; group 2: those undergoing acute immobilization stress, withdrawal from the experiment in 25 hours; and group 3: those undergoing acute immobilization stress, withdrawal from the experiment in 49 hours. The obtained data were processed by statistical methods with the help of the "Biostat" and "Excel" software packages.

Results: In groups 1, 2, and 3, the animals were simulated acute immobilization stress by fixing the animals for 6 hours in bright light. The results of the conducted studies indicate changes in lipid peroxidation and antioxidant system (LPO-AOS) in case of immobilization stress-excitation. In developing free-radical pathology at immobilization stress-excitation, the more expressed disturbance of LPO-AOS, and accordingly the intensity of lipoperoxidation in the structural membrane of all investigated organs was high at the initial stage of exposure.

Conclusion: At 49 hours after immobilization, stress less pronounced influence on the lipoperoxidation process was noted. The increase in the intensity of excessive lipoperoxidation testifies to the inhibited manifestation of AOS in the organism.

Keywords: Immobilization Stress, Antioxidation, Free Radicals, Lipid Peroxidation

Conflicts of Interest: None declared

Funding: The authors pay tribute to the L.N. Gumilyov Eurasian National University for the infrastructure available for this research. This research was funded by the science Committee of the Republic of Kazakhstan, grant no. 0118 RK00662.

*This work has been published under CC BY-NC-SA 1.0 license.

Copyright $\odot$ Iran University of Medical Sciences

Cite this article as: Ilderbayev OZ, Zharmakhanova GM, Okassova AK, Nursafina AZh, Ilderbayeva GO. Cimparison of the performance of lipoperoxidation-antioxidant protection system in rats at different periods under immobilization stress effects. Med J Islam Repub Iran. 2021 (6 Sep);35:113. https://doi.org/10.47176/mjiri.35.113

\section{Introduction}

In recent years, the role of reactive oxygen species

Corresponding author: Dr Oralbek Z. Ilderbayev, o.ilderbayev5963@uoel.uk

${ }^{1 .}$ Faculty of Natural Sciences, L.N. Gumilyov Eurasian National University, Nur-Sultan, Republic of Kazakhstan

2. Department of Natural Science Disciplines, West Kazakhstan Marat Ospanov State Medical University, Aktobe, Republic of Kazakhstan

3. Department of Physiological Disciplines, Semey Medical University, Semey, Republic of Kazakhstan
(ROS) and the free radical processes initiated by them in

\section{$\uparrow$ What is "already known" in this topic:}

There is evidence that immobilization stress $(24 \mathrm{~h})$ causes thymus and spleen involution, and adrenal hypertrophy, and serum cortisol levels increase by $67 \%$ relative to intact animals.

$\rightarrow$ What this article adds:

On the model of immobilization stress of White rats, it was established that the pathological process caused by immobilization stress-induced action activates lipid peroxidation (LPO) and reduction of antioxidant system (AOS) in cells, immunocompetent organs. 
various pathological conditions have been widely discussed. Under phys iological conditions, the activity of these processes is low; and under stress-induced situations, the formation of active oxygen forms is intensified. ROSs, in their turn, lead to excessive and uncontrolled activation of lipoperoxidation processes, which may eventually lead to a pathological state accompanied by impaired functioning of antioxidant system (AOS) enzymes. The reaction of free-radical oxidation (FRO) is initiated by ROS that lead to destruction of biomolecules and chemical modification. Because of the presence in the organism of complex enzyme complexes with specific electron transport prosthetic and coenzyme groups, the oxygen reduction process runs through a multistage mechanism, which minimizes the possibility of formation of highly reactive intermediate oxygen compounds (1).

Oxidative stress results from the disruption of the redox system marked by a notable overproduction of the ROS. There are 4 major sources of ROS, including NADPH oxidases, xanthine oxidases, mitochondria, and nitric oxide synthases (2). Generation of ROS is a physiological process that take place in every aerobic organism. Lipid peroxidation (LPO) is defined as a disturbance in the balance between the production of free radicals and antioxidants in favor of the oxidants. The imbalance between those 2 fractions may potentially lead to cell damage at molecular level. Due to the fact that oxidants are formed at a different rate as a normal product of aerobic metabolism, complex biochemical mechanisms are required to regulate the entire process (3). Free radicals and associated oxidizing agents are ubiquitous and short-lived intermediates formed in aerobic organisms throughout life. These reactive species participate in redox reactions leading to oxidative modifications in biomolecules, among which proteins and lipids are the preferred targets. Despite a wide range of enzymatic and nonenzymatic AOS in mammalian cells, the excess formation of the oxidant causes the accumulation of new products that can disrupt the function and structure of cells, resulting in degeneration and cell death. Physiological levels of oxidants modulate cell functions through homeostatic redox-sensitive cell signal cascades (4).

Free-radical products of LPO and carbonyl compounds; for example, malondialdehyde (MDA), have a robust damaging effect on the mitochondrial genome. Disturbances in the structure and expression of the mitochondrial genome under Vivo conditions are associated with the effect of these very compounds. Products of LPO can cause an increase in nonspecific proton conductivity of the inner mitochondrial membranes. They are classified as valid natural separators. Activation of LPO processes in mitochondria can disrupt oxidative phosphorylation because the effect of the ATP synthesis process depends on the structural integrity of the inner membrane (5). Large flows of $\mathrm{O}-$ $2 \mathrm{O}_{2^{-}}$and $\mathrm{H}_{2} \mathrm{O}_{2}$ lead to oxidation of mitochondrial components and cause mitochondrial dysfunction and even transfer of apoptotic cell death signals (6).
Damaged mitochondria lose barrier function and ability to accumulate calcium ions (7). $\mathrm{Ca}^{2+}$ ions activate many intracellular processes; for example, increase the activity of membrane phospholipases $(8,9)$. The activation leads to the accumulation of free fatty acids and lysophosphatides that disturb the structural organization of lipid and protein complexes in the membranes, which in turn increases the intensity of LPO (10-12). Despite a vast number of clinical and experimental studies, changes in the state of FRO require further research, which makes it necessary to study biochemical aspects of the adaptation, specifically, the biochemistry of immunocompetent organs. Under physiological conditions, LPO is limited by AOS, which can be disrupted by harmful factors (13-18). It is necessary to take into account the importance of the system to determine its function in the formation of the pathological process in animals in different periods under the induced stress-effects in immunocompetent organs and cells. This work aimed to study the role of FRO in immunocompetent organs and cells in mature White rats after 6 hours of immobilization stress action on them.

\section{Methods}

This was an experimental and analitycal study. The study was conducted at Astana Medical University (January-July 2020). The research was performed on 40 White Wistar male rats weighing 200 to $240 \mathrm{~g}$. (period of recruitment: January-February 2020). The animals were kept in normal conditions on a standard food diet with free access to water and food at room temperature of $20{ }^{\circ} \mathrm{C}$ to $22^{\circ} \mathrm{C}$. Two series of experiments were conducted: I series: determination of indices in intact rats (10 rats); II series: determination of indices after 6 hours of immobilization stress. Animals of series II were divided into 3 groups of 10 rats in each. Group 1 was those undergoing acute immobilization stress, withdrawal from the experiment after 1 hour. Group 2 was those rats undergoing acute immobilization stress, withdrawal from the experiment after 25 hours. Group 3 was those undergoing acute immobilization stress, withdrawal from the experiment after 49 hours. The experimental procedures were performed according to EU Directive 2010/63/EU and according to the ethical standards of the local ethics committee of the JSC "Asitana Medical University" protocol No. 4 of 07.09.2017.

Period of exposure: February-May 2020. In 1, 2, and 3 groups in animals simulated acute immobilization stress by fixing animals for 6 hours in bright light. For this experiment, animals were placed in individual plastic compartments adapted for immobilization (length, $20 \mathrm{~cm}$; width, $6 \mathrm{~cm})$. The animals were removed from the experiment in 1, 25, and 49 hours after acute immobilization stress by incomplete decapitation under mild ether anesthesia. Products of LPO and AOS enzymes in organs and cells were determined in studied animals. Lymphocytes were isolated from peripheral blood, and homogenates from the spleen, lymph nodes of the small intestine mesentery, liver, thymus, and adrenal glands were prepared for investigation. They determined the content of conjugated dienes (CD) (19) and MDA (20), 
the activity of the enzyme glutathione reductase (GR), glutathione peroxidase (GP) (21), and catalase (CAT) (22). The follow-up period was 1 month, June through July 2020.

Data collection was processed by statistical method of evaluation of experimental data using "Biostat" and "Excel" software packages using the Student's criterion for evaluating the reliability of differences in individual data groups. Student's t test is a statistical method based on the student's distribution, which is used to determine the statistical significance of differences in mean values. Hypothesis testing was used to determine the $\mathrm{P}$ value on different stages of the research.

\section{Results}

The results of the study showed that 1 hour after the immobilization stress, the CD concentration increased in all investigated objects in comparison with the control group, which indicated the development of a pronounced stress response in response to multihour immobilization. Of these, no significant increase was noted in adrenal gland homogenates and lymph nodes of the small intestine mesentery: from $1.14 \pm 0.07$ to $1.24 \pm 0.10(\mathrm{p}>0.05)$ and from $0.30 \pm 0.02$ to $0.35 \pm 0.02$ ( $p>0.05)$, respectively, while in other studied objects a significant increase of this index was noted: in the liver, it was $195.31 \%(\mathrm{p}<0.001)$; in the thymus, it was $20.45 \%(\mathrm{p}<0.05)$; in the spleen, it was $87.09 \%(\mathrm{p}<0.009)$; and in peripheral lymphocytes, it was $61.90 \%(p<0.05)$ (Table 1). However, 25 hours after immobilization stress from the side of CD concentration, the same picture was noted, with an enormous change in the process of lipoperoxidation. If we switched to digital values, a significant increase could be noted. In the liver, it was $417.18 \%(p<0.001)$; in the thymus, it was $47.72 \%$ $(p<0.009)$; in the spleen, it was $191.93 \%(p<0.001)$; in the adrenal glands, it was $28.07 \%(\mathrm{p}<0.05)$, and in the lymph nodes of the small intestine mesentery, it was $26.67 \%$ $(\mathrm{p}<0.05)$, except for peripheral blood lymphocytes, which contained CD within the limits of control animals (Table 1).

At the next stage of the experiment, the influence of immobilization stress on the production of the primary substance of DC LPO after 49 hours in organs were studied. In comparison with previlous indicators, a sufficient decrease in the formation of CD product in the late period of immobilization stress was revealed. In comparison with the control data of this series of parameters, ambiguous changes were revealed; that is, significant changes occurred in liver and spleen homogenates: in the liver, it was $65.63 \%(p<0.05)$; in the spleen, it was $91.12 \%(p<0.001)$. However, on the other objects of the study, no significant change was revealed, in comparison with the control group, accompanied by upward tendencies ( $\mathrm{p}>0.05$ ).

Considering the results of previous researches and the indicators of deviations it is prossible to ascertain that the most significant increase of CD and MDA level of products in response to immobilization stress-influence has been noted on the early period after stress; namely, on 25 hours after immobilization stress in comparison with the control group of rats. Immobilization stress was also accompanied by increased activity of the studied enzymes in most of the studied tissues and cells (23-25). The results obtained indicate that under the action of immobilization stress, FRO is activated, which may be related to a decrease in the activity of antioxidative enzymes in most of the studied organs. It is known that LPO activation is established on the excessive generation of active oxygen forms, which exceeds the physiological possibilities of AOS after enzyme systems are depleted $(5 ; 10)$. Oxidation of lipids leads to destructive changes in membrane structures and the necessary enzymes associated with them.

The results of the study showed that 1 hour after the immobilization stress, the MDA concentration increased as a CD concentration in all investigated objects, and no significant increase was noted in adrenal gland homogenates and lymph nodes of the small intestine mesenteric lipids: from $0.19 \pm 0.02$ to $0.21 \pm 0.02(\mathrm{p}>0.05)$ and from $0.03 \pm 0.005$ to $0.04 \pm 0.003$ ( $p>0.05$ ), respectively. However, a significant increase was revealed in other investigated objects: in the liver, $100.0 \%(\mathrm{p}<0.001)$, in the spleen $55.17 \%(\mathrm{p}<0.05)$, in the thymus $-38.46 \%(\mathrm{p}<0.05)$, in lymphocytes $-25 \%(\mathrm{p}<0.05)$ (Table 1$)$. The results of the study 25 hours after the immobilization stress from the MDA concentration showed an increase in the product in

Table 1. CD and MDA Concentration in Organs and Lymphocytes of Blood under Immobilization Stress-Effects

\begin{tabular}{|c|c|c|c|c|c|}
\hline \multirow[t]{2}{*}{ Indicators } & \multirow[t]{2}{*}{ Object of study } & \multirow{2}{*}{$\begin{array}{c}\text { I series } \\
\text { Intact rats } \\
(\mathrm{n}=10)\end{array}$} & \multicolumn{3}{|c|}{ II series } \\
\hline & & & $\begin{array}{l}1 \text { group - one hour } \\
\text { after the stress } \\
(\mathrm{n}=10)\end{array}$ & $\begin{array}{l}2 \text { group }-2.5 \text { hours } \\
\text { after the stress } \\
(\mathrm{n}=10)\end{array}$ & $\begin{array}{c}3 \text { group }-49 \text { hours } \\
\text { after the stress } \\
(\mathrm{n}=10)\end{array}$ \\
\hline \multirow[t]{6}{*}{ CD (conditional unit) } & Liver & $0.64 \pm 0.05$ & $1.89 \pm 0.13 * * *$ & $3.31 \pm 0.21 * * *$ & $1.06 \pm 0.11^{*}$ \\
\hline & Spleen & $1.24 \pm 0.08$ & $2.32 \pm 0.21 * *$ & $3.62 \pm 0.24 * * *$ & $2.37 \pm 0.15^{* * *}$ \\
\hline & Thymus & $0.44 \pm 0.03$ & $0.53 \pm 0.03 *$ & $0.65 \pm 0.04 * *$ & $0.45 \pm 0.04$ \\
\hline & Adrenal glands & $1.14 \pm 0.07$ & $1.24 \pm 0.10$ & $1.46 \pm 0.11 *$ & $1.25 \pm 0.13$ \\
\hline & Mesenteric lymphaules & $0.30 \pm 0.02$ & $0.35 \pm 0.02$ & $0.38 \pm 0.03 *$ & $0.34 \pm 0.03$ \\
\hline & Blood lymphocytes & $0.21 \pm 0.02$ & $0.34 \pm 0.03^{*}$ & $0.20 \pm 0 . .02$ & $0.23 \pm 0.02$ \\
\hline \multirow{6}{*}{$\begin{array}{l}\text { MDA (measurement } \\
\text { mole/mgr) }\end{array}$} & Liver & $0.13 \pm 0.01$ & $0.26 \pm 0.02 * * *$ & $0.33 \pm 0.03 * * *$ & $0.18 \pm 0.02 *$ \\
\hline & Spleen & $0.29 \pm 0.03$ & $0.45 \pm 0.03 *$ & $0.32 \pm 0 . .03$ & $0.34 \pm 0.03$ \\
\hline & Thymus & $0.13 \pm 0.01$ & $0.18 \pm 0.01 *$ & $0.20 \pm 0.02 *$ & $0.21 \pm 0.02 *$ \\
\hline & Adrenal glands & $0.19 \pm 0.02$ & $0.21 \pm 0.02$ & $0.24 \pm 0.02$ & $0.23 \pm 0.02$ \\
\hline & Mesenteric lymphaules & $0.03 \pm 0.005$ & $0.04 \pm 0.003$ & $0.07 \pm 0.006^{* * *}$ & $0.08 \pm 0.009 * *$ \\
\hline & Blood lymphocytes & $0.08 \pm 0.006$ & $0.10 \pm 0.007 *$ & $0.07 \pm 0.005$ & $0.09 \pm 0.005$ \\
\hline
\end{tabular}

Note: inequalities with the contact group are significant: * $\mathrm{P}<0.05$; ** $\mathrm{P}<0.009$; *** $\mathrm{P}<0.001$ ( $\mathrm{P}$ values were determined by hypothesis testing). 
the liver homogenates, thymus, and lymph nodes of the small intestine mesentery. The MDA content in the liver is 2.54 times higher $(\mathrm{p}<0.001)$, in the thymus, it was 1.54 times higher $(\mathrm{p}<0.05)$, and in the lymph nodes of the small intestine mesentery, it was 2.33 times higher $(p<0.001)$ than in unstressed animals. In these circumstances, the degree of MDA in other studied objects did not alter (2628).

In the next block of experiments, we investigated (Table 2) the impact of immobilization stress after 1, 25, and 49 hours on the body's AOS in blood organs and lymphocytes. As a result of exposure after 1 hour of immobilization stress action, a significant decrease of CAT, GP, and GR activity in the liver and the spleen was revealed: CATs, in liver homogenates by $22.87 \% \quad(p<0.05)$, in spleen homogenates by $19.83 \%(\mathrm{p}<0.05)$; GP in liver homogenates by $22.91 \%(\mathrm{p}<0.05)$, in spleen homogenates by $28.36 \%(\mathrm{p}<0.05)$; GR in liver homogenates by $24.42 \%$ $(\mathrm{p}<0.05)$, and in spleen homogenates by $27.12 \%(\mathrm{p}<0.05)$.

On the side of peripheral blood lymphocytes, a significant decrease of GR (by $22.77 \%$; $<<0.05$ ) and GP (by $30.25 \% ; \mathrm{p}<0.05)$ and tendency to decrease the activity of enzyme CAT were noted. The same pattern was observed from the thymus and lymph nodes of the small intestine mesentery. In adrenal gland homogenates, there was no significant decrease in the activity of the studied enzymes ( $>0.05$ ). Thus, immobilization stress (in 1 hour after the experiment) was accompanied by pronounced functional activity disorders of the most essential adaptive and adaptive systems of the body and accumulation of toxic compounds in tissues affecting their function. The AOS of the organism as a whole and its tissue and its cells provide binding and alteration of free radicals, prevention of biomolecules formation, and decomposition. At the next stage, the influence of immobilization 25 hours after stress on the activity of enzymes of CAT, GP, and GR in organ and cell homogenates was studied. One of the antioxidant protection enzymes is CAT, which is involved in the decomposition of ROS, thereby increasing the body's adap- tive response. At this stage of the study, for various reasons unknown to us, there was a significant and nonsignificant increase in the activity of all enzymes of this system when excessive lipoperoxidation was previously reported after 25 hours of experience.

For example, a significant increase in the activity of CAT in homogenates of lymph nodes of the small intestine mesentery is 1.51 times $(\mathrm{p}<0.05)$, and it is 1.27 times in adrenal gland homogenates $(p<0.05)$. The activity of GR in homogenates of lymph nodes of small intestine mesentery is 1.62 times $(p<0.01)$, and it is 1.34 times in lymphocytes $(\mathrm{p}<0.05)$. Also, with respect to GP, increased activity was found in lymphocytes, lymphatic nodes, and adrenal glands: in peripheral blood lymphocytes it was from $431.82 \pm 37.23$ to $556.02 \Perp 43.52(\mathrm{p}<0.05)$, in adrenal glands from $167.45 \pm 11.33$ to $352.38 \pm 28.42$ ( $\mathrm{p}<0.001)$, in lymph nodes of the small intestine mesentery from $223.28 \pm 19.13$ to $291.34 \pm 20.13(\mathrm{p}<0.05)$ (Table 2). The enzymes of the AOS are an internal part of the body, and with the help of these enzymes, the AOS is normally able to destroy excess free radicals. In this regard, the increase in the activity of AOS enzymes 25 hours after immobilization stress, brings the body's reaction in a possible manifestation of the second stage of stress on the example of our experiment; as 25 hours after immobilization stress resulted in the expressed activation of enzymes of the body's AOS.

At the next stage of this series, the effect of immobilization stress after 49 hours of exposure to antioxidant protection enzymes was studied. At this stage, a multidirectional change in the activity of antioxidant protection enzymes was observed: a significant increase of CAT activity in lymphocytes was 1.27 times $(\mathrm{p}<0.05)$, GP in liver homogenates 1.25 times $(\mathrm{p}<0.05)$; significant suppression of CAT activity in adrenal glands 1.37 times $(\mathrm{p}<0.05)$, GP in lymphocytes 1.54 times $(\mathrm{p}<0.05)$, in adrenal glands 1.23 times $(\mathrm{p}<0.05)$, and GR in adrenal glands 1.24 times $(\mathrm{p}<0.05)$ (Table 2). The growth in activity of the studied enzymes suggests an increase in the level of active oxygen

Table 2. Activity OF GR, GP, and CAT in organs and lymphocytes of blood under immobilization stress-effects

\begin{tabular}{|c|c|c|c|c|c|}
\hline \multirow[t]{2}{*}{ Indicators } & \multirow[t]{2}{*}{ Object of Study } & I series & \multicolumn{3}{|c|}{ II series } \\
\hline & & $\begin{array}{l}\text { Intact Rats } \\
(\mathrm{n}=10)\end{array}$ & $\begin{array}{c}\text { Group } 1-1 \text { Hour } \\
\text { After Stress }(n=10)\end{array}$ & $\begin{array}{l}\text { Group } 2-25 \text { Hours } \\
\text { After Stress }(n=10)\end{array}$ & $\begin{array}{l}\text { Group 3-49 Hours } \\
\text { After Stress }(n=10)\end{array}$ \\
\hline \multirow[t]{6}{*}{$\mathrm{GR} \mu \mathrm{mol} / \mathrm{g} \min$} & Liver & $24.24 \pm 2.01$ & $18.32 \pm 1.25 *$ & $27.78 \pm 2.014$ & $22.22 \pm 2.05$ \\
\hline & Spleen & $36.13 \pm 3.13$ & $26.33 \pm 2.17 *$ & $43.15 \pm 3.48$ & $29.11 \pm 2.52$ \\
\hline & Thymus & $30.24 \pm 2.54$ & $25.82 \pm 2.03$ & $33.67 \pm 2.677$ & $31.88 \pm 2.38$ \\
\hline & Adrenal glands & $23.13 \pm 1.89$ & $17.64 \pm 1.32 *$ & $25.38 \pm 2.12$ & $18.65 \pm 1.20^{*}$ \\
\hline & Mesenteric lymphaules & $26.09 \pm 2.14$ & $20.27 \pm 1.67 *$ & $42.22 \pm 3.41 * *$ & $30.63 \pm 2.65$ \\
\hline & Blood lymphocytes & $9.31 \pm 0.83$ & $7.19 \pm 0.53^{*}$ & $12.48 \pm 1.17^{*}$ & $8.11 \pm 0.66$ \\
\hline \multirow[t]{6}{*}{$\mathrm{GP} \mu \mathrm{mol} / \mathrm{g} \min$} & Liver & $166.13 \pm 14.47$ & $128.07 \pm 8.35^{*}$ & $261.94 \pm 20.22 *$ & $208.55 \pm 15.32 *$ \\
\hline & Spleen & $256.35 \pm 21.12$ & $183.65 \pm 12.63 *$ & $244.38 \pm 20 . .37$ & $227.63 \pm 18.98$ \\
\hline & Thymus & $117.68 \pm 8.57$ & $112.36 \pm 9.67$ & $137.25 \pm 10 . .11$ & $121.33 \pm 10.25$ \\
\hline & Adrenal glands & $167.45 \pm 11.33$ & $145.18 \pm 11.28$ & $352.38 \pm 28.42 * * *$ & $136.67 \pm 9.85 *$ \\
\hline & Mesenteric lymphaules & $223.28 \pm 19.13$ & $212.75 \pm 17.37$ & $291.34 \pm 20.13^{*}$ & $245.32 \pm 17.38$ \\
\hline & Blood lymphocytes & $431.82 \pm 37.23$ & $301.19 \pm 22.74 *$ & $556.02 \pm 43.52 *$ & $279.65 \pm 20.24 *$ \\
\hline CAT \% (losses & Liver & $75.35 \pm 6.14$ & $58.12 \pm 4.39^{*}$ & $80.05 \pm 7.45$ & $63.52 \pm 4.77$ \\
\hline \multirow[t]{5}{*}{$\left.\mathrm{H}_{2} \mathrm{O}_{2}\right)$} & Spleen & $60.16 \pm 4.77$ & $48.23 \pm 3.01 *$ & $72.34 \pm 6.43$ & $73.86 \pm 5.56$ \\
\hline & Thymus & $54.46 \pm 4.05$ & $37.63 \pm 3.02 *$ & $63.57 \pm 4.77$ & $53.14 \pm 4.32$ \\
\hline & Adrenal glands & $62.36 \pm 5.24$ & $60.38 \pm 4.55$ & $79.16 \pm 5.25 *$ & $45.33 \pm 3.04 *$ \\
\hline & Mesenteric lymphaules & $51.24 \pm 4.26$ & $41.29 \pm 2.28 *$ & $77.08 \pm 6.11^{*}$ & $46.23 \pm 3.15$ \\
\hline & Blood lymphocytes & $90.13 \pm 8.34$ & $73.36 \pm 5.58$ & $90.23 \pm 7.37$ & $114.34 \pm 8.11 *$ \\
\hline
\end{tabular}

Note: dissimilarities with the contact group are significant: $* \mathrm{P}<0.05 ; * * \mathrm{P}<0.01 ; * * * \mathrm{P}<0.001$. 
forms and their peroxide compounds under immobilization stress, which indicates a change in the integrity of the cell membrane.

\section{Discussion}

Cell death may occur as a result of the lack of energy (7). According to modern concepts, stress is a protective neuroendocrine reaction caused by changes in the activity of both the nervous system and the hypothalamuspituitary-adrenal system $(8,9)$. According to study by Narizhnaya et al, immobilization stress (24 h) causes thymus and spleen involution, adrenal hypertrophy, and serum cortisol levels increase by $67 \%$ relative to intact animals (10). Pertsov et al in the paper "State of Stress Marker Organs in Rats With Different Behavioral Activity Under Multiple Stressors" studied changes in the relative weight of stress marker organs in rats with different parameters of behavior in the "open field" test after repeated stress loads on a model of daily 4-hour immobilization during 8 days. In behaviorally passive rats, thymus and spleen involution was noted. In inactive animals, the mass of these organs practically did not change but decreased after repeated stress exposures on the third and especially on the eighth day of the study (11). Other objects-targets of harmful influence of stressogenic factors are also known. According to the Russian scientists' research, in the case of immobilization and hypokinetic stress, there are various violations of cardiovascular, musculoskeletal, and endocrine systems activity, metabolic processes, and decrease of immune system activity $(12,13)$. Ghezzi believes that the environmental factors may cause biological reactions, such as oxidative stress and inflammation, because of chemical, physical, or psychological changes (14).

Our researches have established that the pathological condition caused by immobilization stress in 49 hours is followed by the increase of MDA in liver, thymus and lymph nodes of experimental rats: 1.38 times, 1.62 times $(\mathrm{p}<0.05)$ and 2.67 times $(\mathrm{p}<0.001)$ accordingly in comparison with control animals. In other objects of research, the effect of experimental immobilization stress during 49 hours was followed by nonsignificant accumulation of MDA $(p>0.05)$ in spleen homogenates, adrenal glands, and lymphocytes of peripheral blood in comparison with the control group (I group). When comparing the impact of immobilization stress on the formation of MDA in the organs and lymphocytes and on the indicator of deviation showed a significant increase in the liver, thymus, and lymph nodes of the small intestine mesentery at 25 with 49 hours after the experience. Thus, excessive lipoperoxidation may have led to destructive changes in the membrane structures of the above objects. In our example, increased content of lipoperoxidation products is typical for tissues with high regenerated and metabolic process. The data obtained in the study showed that under immobilization stress, the activity of the foregoing enzymes in the thymus, spleen, liver, and mesenteric lymph nodes did not change significantly, but showed an opposite change in comparison with the unstressed group $(p>0.05)$.

Adaptive processes of an organism are known to depend on a great extent on the completeness of the AOS function. The pathological process, induced by experimental immobilization stress, is accompanied by expressed infringements of functional activity of the most crucial adaptation systems of the organism and subsequently by an accumulation of toxic for organism compounds in tissues, affecting their primary function. The AOS of an organism provides binding and alteration of excessively formed free radicals, prevention of biomollecules formation, and degradation (11-13).

\section{Conclusion}

The results of the conducted researches confirm the changes in lipoperoxidation and AOS under immobilization stress-effects. The intensity of lipoperoxidation in the structural membrane of all investigated organs was high at the initial stage. The increase of intensity of excessive lipoperoxidation confirms the inhibited display of AOS in an organism. Infringements of functional interconnections of catalytic glutathione redox system and longtime tension of AOS links, most likely, contribute to a decrease of antioxidant status of an organism that sets before the necessity to develop perspective methods of adaptation correction.

In our example, we did record all the stages of stress; with acute stress, sometimes there is only the stage of "anxiety." The stage depends on the level of the stressor factor. To identify and confirm all stages of stress, up to the stage of "exhaustion," we think it is possible to use a more powerful stressor or chronic stressor. Nevertheless, that is the task of future research work. The results of this research allow us to formulate the following conclusions:

1. On the model of immobilization stress of White rats, it was established that the pathological process caused by immobilization stress-induced action activates LPO and reduction of AOS in cells, immunocompetent organs.

2. In developing free-radical pathology under immobilization stress-induced action, more pronounced LPO-AOS disorder occurs at the initial stage of exposure.

3. 49 hours after immobilization stress, a less pronounced influence on the lipoperoxidation process was observed.

\section{Acknowledgment}

The authors pay tribute to the L.N. Gumilyov Eurasian National University for the infirastructure available for this research. This research was funded by the science Committee of the Republic of Kazakhstan, grant no. $0118 R K 00662$.

\section{Conflict of Interests}

The authors declare that they have no competing interests.

\section{References}

1. Bezruchko NV, Rubtsov GK, Ganyaeva NB, Kozlova GA, Sadovnikova DG. Catalase of biological environments of the human body and its clinical and biochemical significance in the assessment of endotoxicosis. TSPU Bull. 2012;7:94-99.

2. Su H, Wan C, Song A, Qiu Y, Xiong W, Zhang C. Oxidative stress 
and renal fibrosis: mechanisms and therapies. In: B.C. Liu, H.Y. Lan, L.L. (Eds.). Renal Fibrosis: Mechanisms and Therapies. Advances in Experimental Medicine and Biology. Singapore: Springer, 2019, p 585-604. doi: 10.1007/978-981-13-8871-2 29

3. Pruchniak MP, Araźna M, Demkow U. Biochemistry of oxidative stress. In: M. Pokorski (Eds.). Advances in Clinical Science. Cham: Springer, 2016, p 9-19. doi: 10.1007/5584_2015_161.

4. Radi R. Oxygen radicals, nitric oxide, and peroxynitrite: Redox pathways in molecular medicine. Proceed Natl Acad Sci. 2018;115(23):5839-5848.

5. Quijano C, Castro L, Peluffo G, Valez V, Radi R. Enhanced mitochondrial superoxide in hyperglycemic endothelial cells: Direct measurements and formation of hydrogen peroxide and peroxynitrite. Am J Phys-Heart Circul Phys. 2007;293:3404-3414.

6. Murphy MP. Understanding and preventing mitochondrial oxidative damage. Biochem Soc Trans. 2016;44:1219-1226.

7. Cadenas E, Davies KJ. Mitochondrial free radical generation, oxidative stress, and aging. Free Rad Biol Med. 2000;29:222-230.

8. Vinogradov VV. Stress: morphobiology of the adrenal cortex. Minsk: Belarusskaya Navuka, 1998.

9. Zaychik ASh, Churilov LP. Fundamentals of general pathophysiology. Saint Petersburg: Albi, 1999.

10. Narizhnaya NV, Maslov LN, Vychuzhanova EA, Sementsov AS, Podoksenov YuK, Portnichenko AG, Lishmanov YuB. Influence of hypoxic preconditioning on stress response indicators in rats. Bull Exper Biol Med. 2015;159(4):439-441.

11. Pertsov SS, Grigorchuk OS, Koplik EV, Abramova AYu, Chekmareva NYu, Chekov VV. State of stress marker organs in rats with different behavioral activity under multiple stressors. Bull Exper Biol Med. 2015;160(7):25-29.

12. Kumskova JG, Rassokhin AG, Tseilikman VE, Pavlov VI. Changes in the blood system during long-term hypokinesia. Bull Chelyabinsk State Pedagl Univer. 2000;9(1):90-93.

13. Khulup GYa, Vladimirskaya TE, Shved IA. Structural damage of cardiomyocytes under immobilization stress. Health. 2005;9:9-11.

14. Ghezzi P, Floridi L, Boraschi D, Cuadrado A, Manda G, Levic S, et al. Oxidative stress and inflammation induced by environmental and psychological stressors: A biomarker perspective. Antioxid Redox Signal. 2017;28:9-15.

15. Hybertson BM, Gao B, Bose SK, McCord JM. Oxidative stress in health and disease: the therapeutic potential of Nrf2 activation. Mol Asp Med. 2011;32:234-246.

16. Lipinski B. Hydroxyl radical and its scavengers in health and disease. Oxid Med Cell Longev. 2011:809696.

17. Rumyantseva GM, Muraviev AI, Levina TM. Impact of radiation and non-radiation factors on the mental health of the population affected by the radiation accident. Med Radiol Radiat Saf. 2011;4:2531.

18. Sharma N. Free radicals, antioxidants and disease. Biol Med. 2014;6(3):2-6.

19. Gavrilov VB, Mishkorudnaya MI. Spectrophotometric determination of the content of lipid hydroperoxides in blood plasma. Labor Work. 1983;3:33-36.

20. Konyukhova SG, Markin SG, Konyukhov AA, Fedorova TN. Lipid peroxidation and methods of determining products of lipid peroxidation in biological fluids. Labor Work. 1989;9:40-46.

21. Vlasova SN, Shabunina EI, Pereslegina IA. Activity of glutathionedependent erythrocyte enzymes in chronic liver diseases in children. Labor Work. 1990;8:19-22.

22. Korolyuk MA, Ivanova LI, Mayorova NO, Tokarev VE. Method for determining catalase activity. Labor Work. 1988;1:16-19.

23. Zhakupova AA, Maulanov AZ, Biyashev BK, Biyashev KB, Sarsembaeva NB. Histological study of the interaction of the escherichia with epithelium of the small intestine of rats. Adv Environ Biol. 2014;8(10):553-555.

24. Biyashev KB, Biyashev BK, Makbuz AZ. Prevalence of causative agents of emergent food zoonotic diseases in animals, animal origin products and environmental objects. Biol Med. 2016;8(2):BM-169-16.

25. Horalskyi L, Kovalchuk O, Sokulskyi I. Pathamorphological changes of cats pancreata under acute pancreatitis. Sci Horiz. 2020;8(93):149-157.

26. Spicuzza L, Parisi GF, Tardino L, Ciancio N, Nenna R, Midulla F, Leonardi S. Exhaled markers of antioxidant activity and oxidative stress in stable cystic fibrosis patients with moderate lung disease. J Breath Res. 2018;12(2):026010.
27. Parisi GF, Cutello S, Di Dio G, Rotolo N, La Rosa M, Leonardi S Phenotypic expression of the p.Leu1077Pro CFTR mutation in Sicilian cystic fibrosis patients. BMC Res Notes. 2013;6(1):461.

28. Zykova SS, Tsaplin GV, Talismanov VS, Bulatov IP, Popkov SV, Karmanova O. Antioxidant activity and acute toxicity of new n4substituted5-(1,2,4-triazole-1-ylmethyl)-1,2,4-triazole-3-thiones and sderivatives. Int J Pharm Res. 2021;13(1):309-313. 